\title{
The G protein-coupled receptors in the pufferfish Takifugu rubripes
}

\author{
Anita Sarkar ${ }^{\dagger}$, Sonu Kumar ${ }^{\dagger}$, Durai Sundar ${ }^{*}$ \\ From The Ninth Asia Pacific Bioinformatics Conference (APBC 2011) \\ Inchon, Korea. 11-14 January 2011
}

\begin{abstract}
Background: Guanine protein-coupled receptors (GPCRs) constitute a eukaryotic transmembrane protein family and function as "molecular switches" in the second messenger cascades and are found in all organisms between yeast and humans. They form the single, biggest drug-target family due to their versatility of action and their role in several physiological functions, being active players in detecting the presence of light, a variety of smells and tastes, amino acids, nucleotides, lipids, chemicals etc. in the environment of the cell. Comparative genomic studies on model organisms provide information on target receptors in humans and their function. The Japanese teleost Fugu has been identified as one of the smallest vertebrate genomes and a compact model to study the human genome, owing to the great similarity in its gene repertoire with that of human and other vertebrates. Thus the characterization of the GPCRs of Fugu would provide insights to the evolution of the vertebrate genome.

Results: We classified the GPCRs in the Fugu genome and our analysis of its 316 membrane-bound receptors, available on the public databases as well as from literature, detected 298 GPCRs that were grouped into five main families according to the GRAFS classification system (namely, Glutamate, Rhodopsin, Adhesion, Frizzled and Secretin). We also identified 18 other GPCRs that could not be grouped under the GRAFS family and hence were classified as 'Other 7TM' receptors. On comparison of the GPCR information from the Fugu genome with those in the human and chicken genomes, we detected 96.83\% (306/316) and 96.51\% (305/316) orthology in GPCRs among the Fugu-human genomes and Fugu-chicken genomes, respectively.

Conclusions: This study reveals the position of pisces in vertebrate evolution from the GPCR perspective. Fugu can act as a reference model for the human genome for other protein families as well, going by the high orthology observed for GPCRs between Fugu and human. The evolutionary comparison of GPCR sequences between key vertebrate classes of mammals, birds and fish will help in identifying key functional residues and motifs so as to fill in the blanks in the evolution of GPCRs in vertebrates.
\end{abstract}

\section{Background}

G protein-coupled receptors (GPCRs) constitute one of the largest and most ancient super-families of integral trans-membrane receptor proteins that act as cellular receptors and play a central role in the signal transduction in eukaryotes [1-4]. They are perhaps the most versatile of all the known proteins in the human genome [5] and

\footnotetext{
* Correspondence: sundar@dbeb.iitd.ac.in

† Contributed equally

Department of Biochemical Engineering and Biotechnology, Indian Institute of Technology (IIT) Delhi, New Delhi, India
}

hence are the focus of intense pharmaceutical and academic research [6] as they form one of the prime transduction pathways through which acceptance of a signal by a cell can principally occur, the other being tyrosine kinase receptors [7]. Abnormalities in cell signaling by GPCRs are the root cause of wide-spread disorders like asthma, peptic ulcers, hypertension, type II diabetes etc. [8]. GPCRs have triumphed throughout the course of evolution and can probably be traced back to a time before the divergence of plants and animals [5] and possibly even exist in protozoa, though not characterized, yet [9]. Their importance can be 
gauged from their presence as well as abundance in almost all eukaryotic genomes [10].

The availability of complete sets of putative members of a family from diverse species provides the basis for cross-genome comparative studies. The Japanese pufferfish, Takifugu rubripes, having a genome that is oneeighth the size of that found in human, is among the smallest vertebrate genomes and thus an apt reference for annotating the human genome. Teleosts diverged about 500 million years ago from other phyla and are ancestors of tetrapods. Comparing the genomes of Fugu and the green spotted pufferfish (Tetraodon nigroviridis), it is observed that about $75 \%$ of the duplication events appear to have happened before the Takifugu and Tetraodon lineages separated [11]. Both these teleost species serve as model genomes but are non-redundant since the two, being separated by approximately 18 to 30 million years, provide an improved annotation on both sides.

We have classified the GPCRs present in the Takifugu rubripes genome according to the GRAFS classification system and compared it to GPCRs present in the human, chicken and the Tetraodon nigroviridis genomes, which has added to the information of GPCR evolution alongside vertebrate evolution (from data available from the non-redundant public databases) and detected very high orthology between Fugu-human and Fugu-chicken. Additionally we also compared the GPCRs between the Japanese and the green spotted pufferfish for perspective and found that the two pufferfishes had comparable receptors in this superfamily of proteins.

\section{Results and discussion}

Our primary objective was to classify the GPCRs of the Fugu (Japanese or tiger pufferfish) genome according to the GRAFS classification system [12], that were available with the non-redundant public databases of NCBI [13] and UniProtKB [14] (where A-F classification system is followed [15]) and from previously published literature [2], as the majority of GPCRs in all eukaryotes, starting from the nematodes in the evolutionary ladder, can be categorized in lieu of the GRAFS system (Figure 1). We

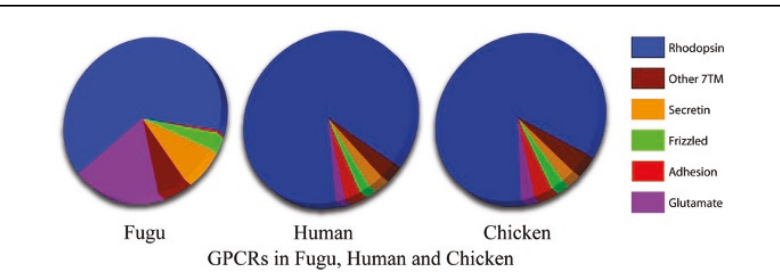

Figure 1 GPCR distribution in Fugu, Chicken and Human: The figure illustrates a comparative account of the GPCRs present in the representatives of 3 vertebrate classes. also compared the GPCRs between the two puffer fishes to understand the pattern of evolution among teleosts that has been characterized according to GRAFS [11].

Fugu comprises fewer GPCRs than either human and chicken (Table 1). Also our dataset has 150 GPCRs less than that reported in Tetraodon nigroviridis [11]. Except for 10 Fugu receptors, all others find matches in the human GPCRs, while all but 11 find counterparts in the chicken GPCR sub-set. All Fugu GPCRs found orthologs in Tetraodon nigroviridis though, unlike Fugu, most Tetraodon GPCR sequences in the public databases still did not have a clearly defined function. We observed that there are some unique receptors in Fugu which are not present in humans like the pheromone receptors, while some are conspicuous with their absence in Fugu, such as the melanocortin3 (MC3) receptors which are found in human. 18 Fugu receptors did not confirm to the requirements of the GRAFS classification and hence were grouped under the Other 7TMs. For better understanding and clarity in viewing the phylogenetic tree, we grouped the families as Rhodopsins and Non-Rhodopsins (Table 2). A very high orthology was detected between the receptors of chicken and human when compared to those in Fugu (Table 3), keeping with the attribute of Fugu as a reference model for the human genome. Also all Fugu GPCRs found counterparts in Tetraodon nigroviridis (Table 2), though the orphans could not be compared between the sub-families as this detail was not found for Tetraodon nigroviridis.

\section{Non-Rhodopsins \\ Glutamate (58 receptors)}

Figure 2 describes the repertoire of the Fugu GPCRs grouped together as the Non-Rhodopsins, which includes Glutamate, Adhesion, Frizzled, Secretin and Other 7TM families. In our study, we observe that out of the 58 Glutamate receptors in Fugu, all found orthologs in the Tetraodon, human and chicken GPCRs but these did not necessarily have the same function. At the sub-family

Table 1 GPCRs in Fugu, Human, Chicken and Tetraodon nigroviridis

\begin{tabular}{lccccc}
\hline $\begin{array}{l}\text { Receptor } \\
\text { family }\end{array}$ & Fugu & Human & Chicken & $\begin{array}{l}\text { Tetraodon } \\
\text { nigroviridis }\end{array}$ & \\
\hline Glutamate & 58 & 15 & 15 & 36 & \\
Rhodopsin & & & & & \\
$\alpha$ & 110 & 89 & 92 & 137 & +26 \\
$\beta$ & 20 & 35 & 45 & 88 & orphans \\
$\gamma$ & 14 & 59 & 46 & 42 & \\
$\delta$ & 60 & 518 & 290 & 75 & \\
Adhesion & 2 & 24 & 22 & 29 & \\
Frizzled/Tas2 & 10 & 24 & 14 & 12 & \\
Secretin & 24 & 15 & 14 & 21 & - \\
Other 7TM & 18 & 23 & 19 & & \\
\hline
\end{tabular}


Table 2 Rhodopsin and Non-Rhodopsin receptors in Fugu, Human, Chicken and Tetraodon nigroviridis

\begin{tabular}{lcccc}
\hline Receptor family & Fugu & Human & Chicken & Tetraodon nigroviridis \\
\hline Non-Rhodopsin & 112 & 101 & 62 & 98 \\
Rhodopsin & & & & \\
Olfactory & 56 & 460 & 229 & 22 \\
Non-olfactory & 148 & 241 & 61 & 346 \\
\hline
\end{tabular}

level, the 9 Fugu metabotropic Glutamate (GRM) and the lone $\mathrm{Ca}^{2+}$-sensing (CASR) showed conserved function but this was not true for the 36 V2Rs (pheromone receptors of Fugu) which are absent in human and chicken. The V2Rs found orthologs in the CASR and GRM receptors of chicken and human. The 12 type 1 taste (TAS1) receptors in Fugu matched with various other members of the type 1 receptors in both human and chicken. Interestingly, the corresponding receptors were exactly the same in human and chicken, which occurs probably due to an evolutionary diversification at a stage later than pisces in the course of vertebrate evolution. The presence of TAS1 receptors in both the pufferfishes points to the presence of chemosensory glutamate receptors prior to the evolution of land vertebrates. Like the chicken GPCR subset, Fugu also seems to lack the ortholog for the GABABR (gamma aminobutyric acid-binding receptor) though 4 such representatives were detected in Tetraodon nigroviridis. Probably, this is observed due to a different mode of function of GABA receptors in Fugu and chicken as compared to Tetraodon nigroviridis and human.

\section{Adhesion ( 2 receptors)}

The adhesion sub-family is known to have immunological functions as well as plays important roles in the central nervous system [16]. They are unique in comprising of certain motifs, rich in glycosylation sites and proline residues, occurring in the long (200-800 amino acids) $\mathrm{N}$-termini, that are likely-players in cell adhesion $[17,18]$. This family has been referred to by many other names due to some other unique characteristics, for instance, it has been called EGF-TM7 to emphasise the presence of epidermal growth factors (EGF) domains in its $\mathrm{N}$-termini, LN-TM7 receptors, due to its long

Table 3 Percentage orthology of Fugu GPCRs with Human and Chicken

\begin{tabular}{lcc}
\hline Organism & $\begin{array}{c}\text { Number of GPCRs orthologous to } \\
\text { Fugu }\end{array}$ & $\begin{array}{c}\text { Percentage } \\
\text { orthology* }\end{array}$ \\
\hline Human & 306 & 96.83 \\
Chicken & 305 & 96.51 \\
Fugu & 316 & N.A. \\
\hline
\end{tabular}

* The data includes all those sequences that are homologous to the GPCRs in the Human and Chicken GPCR sub-sets. variable $\mathrm{N}$-termini, as already mentioned above, and also termed B2 due to their distant similarity with secretin receptors [19]. Only two adhesion receptors could be detected in Fugu from the sequence dataset collected. Both corresponded to the Ig-hepta/GPR116 that is found in the chicken and human datasets of GPCRs, while 29 receptors were grouped in to this family for Tetraodon nigroviridis. No GPCRs corresponding to the BAI, CELSR, EMR, ETL, HE6 and LEC sub-families were found for Fugu in the public databases.

CD97 belongs to the B family of G protein-coupled receptors (GCPRs). Subfamily B2 contains cell surface molecules with long extracellular N-termini (LNBTM7). They are putative cell-surface signaling molecules induced in the activated leukocytes and are highly expressed in regions of inflammation (indicating a probable protective and destructive immune responses), besides being expressed in smooth muscle cells and malignant tumors [20-22]. These receptors are present in Tetraodon and human but lack orthologs in Fugu and chicken, and were probably lost in the lineage leading to chicken.

\section{Frizzled/taste 2 (10 receptors)}

The Frizzled/taste 2 sub-family are a comparatively recent addition to the GPCR family, which mediate signals from the secreted glycoproteins, thus controlling cell fate, polarity and proliferation during metazoan development [12]. They are receptors having 200 amino acid long $\mathrm{N}$-termini with conserved cysteine residues that are expressed in the tongue and palate epithelium and probably act as bitter taste receptors, though their function is not quite clear.

This sub-family is one of the most highly-conserved among all GPCRs found in flies, fish and mammals, indicating an evolutionary pattern far-removed from the other GPCR families. In comparison to the 10 frizzled receptors of Fugu, the human GPCR repertoire has 24, while the count reaches 11 in the chicken sub-set. Tetraodon has been reported to have 12 frizzled/ smoothened/ TAS2 GPCRs.

The taste 2 GPCRs, which seem to have arisen much later, being conspicuously absent in flies, roundworm (Caenorhabditis elegans) and Fugu (Takifugu rubripes), have a considerable representation in the mouse and human GPCR sub-sets and a sole member in zebra-fish. In fact, this is one of the only two receptor types (the other being vomeronasal receptors) that have arisen after the split of tunicates from the lineage leading to the vertebrates. This receptor-type is not well-conserved; in fact they are among those that have evolved most rapidly in the past 100-200 million years in mammals. 


\section{Fugu Non-Rhodopsins}

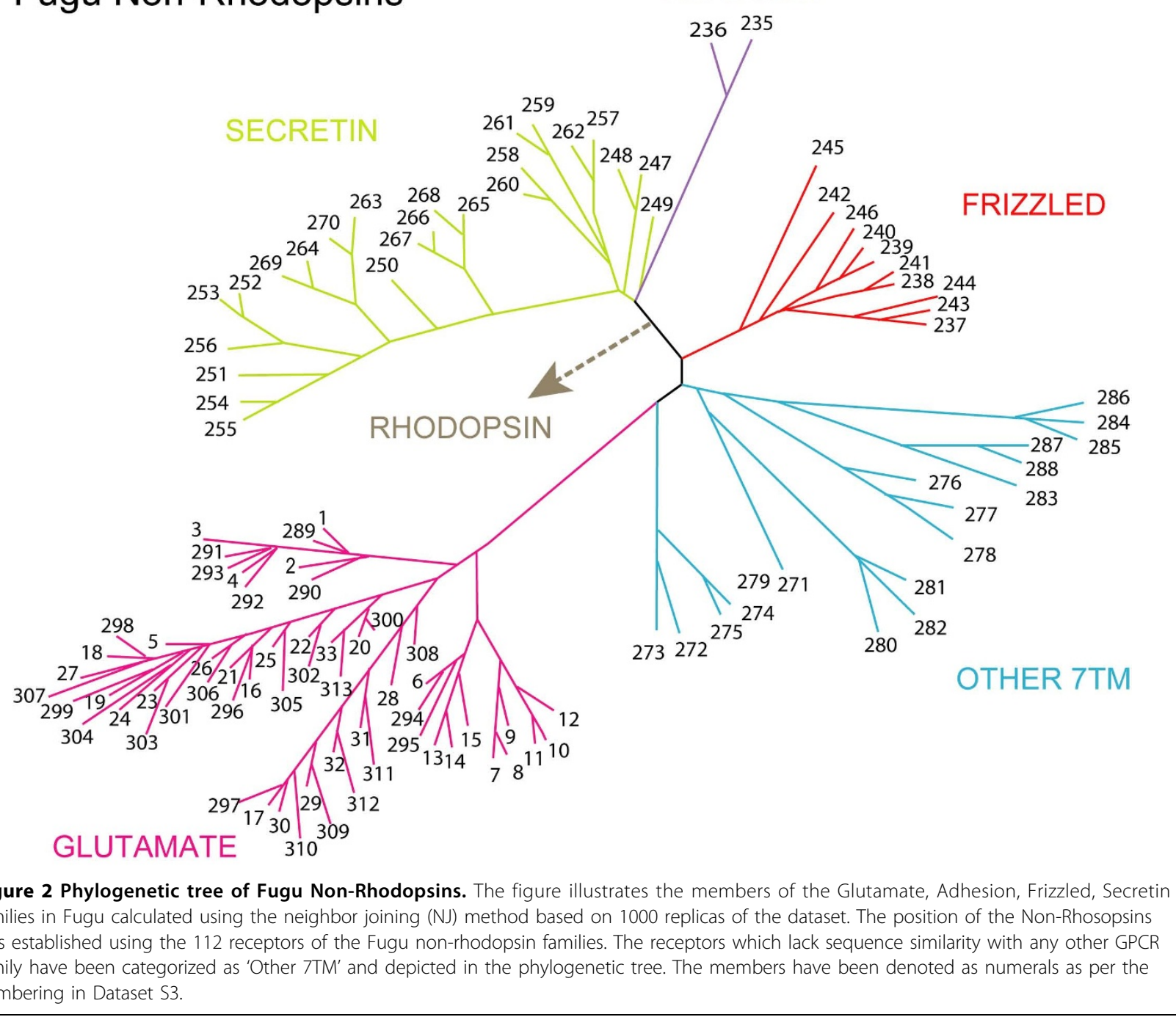

\section{Secretin (24 receptors)}

Secretin is one of the sub-families (besides Adhesion) that appeared on the GRAFS classification system by the splitting of class B of the A-F system. The secretins were found to be descendents of the adhesion family [23] and has structural similarity with the latter in their transmembrane regions. The secretin receptors comprise of at least six highly conserved cysteine bridges in their Ntermini and bind to large peptide ligands like hormones and neuropeptides [24]. They are well represented in all vertebrates as well as in tunicates, fruitfly and nematodes. They are gastro-intestinal hormones that regulate the ion (bicarbonate and potassium) and enzyme secretion from the pancreas. In Fugu, the secretin sub-family comprises of 2 calcitonin receptors (CALCR), 1 corticotropinreleasing hormone receptor (CRHR), 1 growth hormonereleasing hormone (GHRHR), 6 pituitary adeylate cyclase-activating peptide (PACAP), 6 parathyroid hormone receptors (PTHR) and 8 vasoactive intestinal peptide receptors (VIPR), bringing it to a total of 24, while in human and chicken there are 15 and 14 of these GPCRs, respectively. Tetraodon has 21 secretin receptors with at least $73 \%$ sequence similarity with the Fugu secretin receptors. The secretin and the VIPRs are thought to share a common ancestor, with secretin receptors appearing approximately 310 million years ago either due to gene duplication or from a glucagon ligand.

\section{Rhodopsins (56 olfactory, 148 non-olfactory)}

The Rhodopsins constitute the largest chunk ( 64.5\%) of the Fugu GPCR repertoire, comprising of 204 receptors, keeping with the trend in numbers seen in the GPCR repertoires of all vertebrates. Rhodopsins in the GRAFS system correspond to the class A of the A-F classification 
system. This is the first family of GPCRs whose three dimensional structure was determined, thus serving as the foundation of structural studies for the understanding of these special proteins. The rhodopsins have a structure that is different from adhesion, frizzled, secretin and majority of the glutamate receptors, as the rhodopsins have short N-termini, unlike the others mentioned. The rhodopsin binding cavity seems to be between the transmembrane regions in contrast to the other GPCR families where the $\mathrm{N}$-terminal plays the pivotal role in ligand-binding, though the ligand-binding domain of luteinizing hormone ( $\mathrm{LH})$, follicle stimulating hormone (FSH), leucine-rich-repeat containing GPCR (LG) and thyrotropin stimulating hormone (TSH) receptors of the $\delta$ sub-family lie in the N-termini [12] (Figure 3).
The Rhodopsin family is systematically categorized in to 4 groups based on experimental phylogenetic investigations: $\alpha$ (amine-binding receptors), $\beta$ (only peptide-binding receptors), $\gamma$ (receptors that bind to neuropeptides like somatostatins, galanin, opioids and chemokines etc.) and $\delta$ (olfactory, purine and glycoprotein receptors) [12].

\section{$\alpha$-rhodopsins (110 receptors)}

The $\alpha$-group includes 24 amine receptors, 14 opsins and 72 members of the MECA cluster in the Fugu GPCR dataset. There are a total of $701 \alpha$-rhodopsins in human while 92 of these are present in chicken and 137 in Tetraodon nigroviridis. Some $\alpha$-rhodopsin sub-groups like the melanocortin (MC) and endothelial differentiation G-protein coupled receptors (EDGRs) are very well-

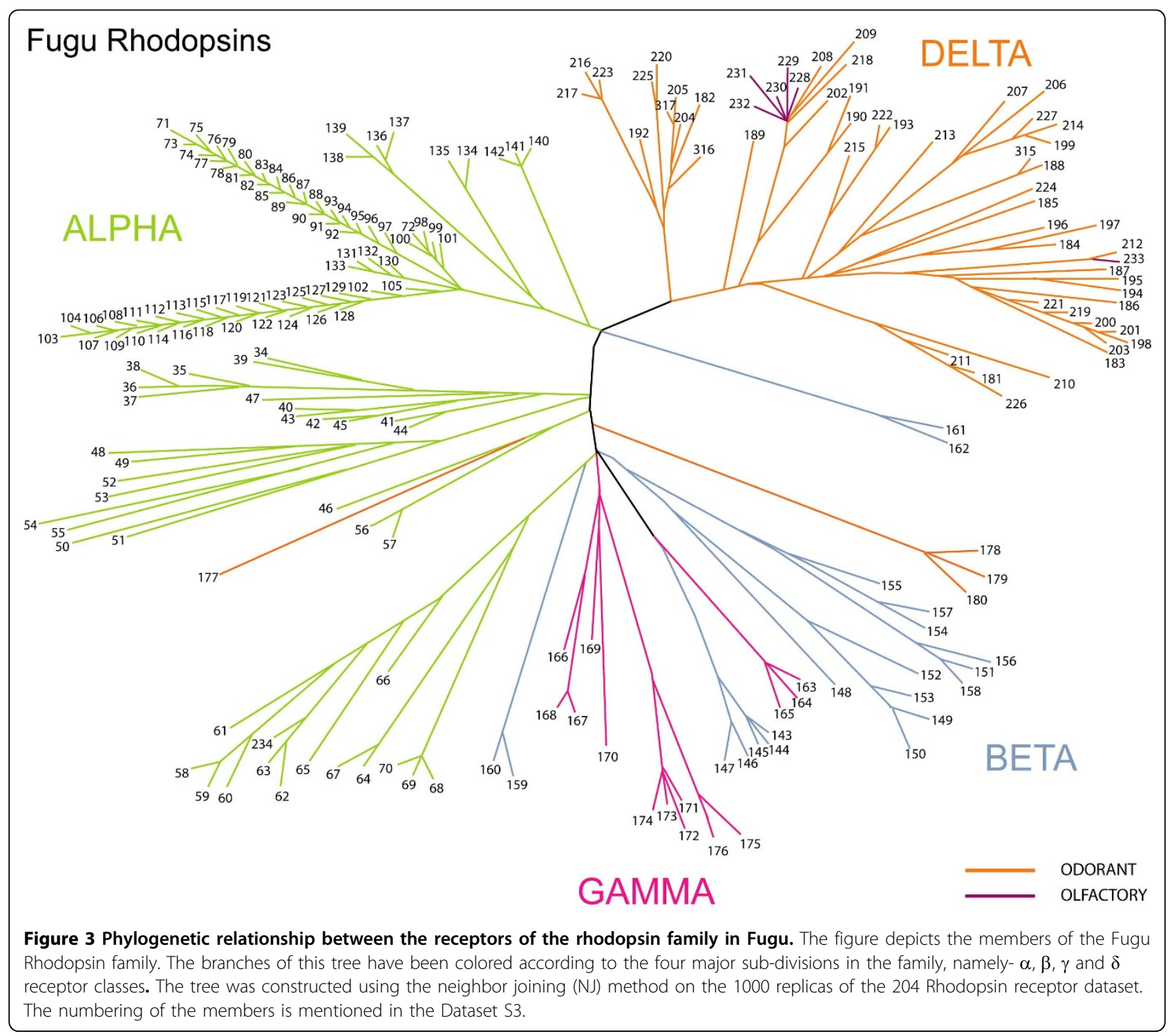


conserved. All but 3 out of the 63 Fugu MC receptors have one-to-one orthology with the human and chicken sub-sets, and both the EDGR receptors found exact matches in both human and chicken. The MC receptors (MC4 and MC5) arose early in the evolution of vertebrates, still displaying a remarkable conservation in their sequences, especially in the binding and activation domains [25]. Except the MC3 receptors, which Fugu lacks, its MC receptors have evident similarities with those found in mammals, especially in their pharmacological characters which indicates that they bind to melanocortin peptides with high potency and respond well in their presence, thus playing essential roles in pigmentation regulation, energy homeostasis and the production of steroids [26-28]. Fugu also lacks both prostaglandin and melatonin receptors of the $\alpha$-subfamily but has 6 receptors each in the serotonin and dopamine subgroups, 1 muscarinic, 2 trace amines and 9 adrenergic receptors, all displaying one-to-one orthology with the human and chicken GPCRs. Fugu contains a total of 14 opsins: 5 rod pigments, 6 cone visual pigments, 3 encephalopsins/ TMT (Teleost Multiple Tissue) opsins and no peropsins, melanopsins and retinal G-protein receptors. The MECA (MC, EDGR, Cannabinoid, ADORA/Adenosine receptor) cluster contains the highest number (72) of receptors in the rhodopsin family, out of which the majority (63) are $\mathrm{MC}$ receptors.

\section{$\beta$-rhodopsins (20 receptors)}

Though this group has no main branches, it consists of 20 peptide-binding receptors of 17 different types. In the Fugu GPCR repertoire, this family is constituted by 10 neuropeptide Y (NPY), 5 neuropeptide (NPFF), 2 endothelin-related receptors (EDNR), 2 arginine-vasopressin receptors (AVPR) and 1 tachykinin receptors (TACR), but no hypocretin receptors (HCRTRs), cholecystokinin receptors (CCKs), gastrin-releasing peptide receptors (GRPRs), neuromedin B receptors (NMBRs), uterinbombesin receptors (BRS3), neurotensin receptors (NTSRs), growth hormone secretagogues receptor (GHSRs), neuromedin receptors (NMURs), thyrotropin releasing hormone receptors (TRHRs), ghrelins, gonadotropin releasing hormone receptors (GNRHRs), oxytocins or orphans. The human and chicken GPCR sub-sets have 35 and $45 \beta$ rhodopsin receptors respectively, as compared to the 20 detected in Fugu and 88 in Tetraodon nigroviridis. All of the 10 Fugu NPY receptors show orthology with the human and chicken NPY receptors. Fugu has representatives of Y2, Y4 (also known as pancreatic polypeptide receptors or PP-receptors), Y7, Y8 and YY receptors types in this sub-class. The Y1, Y5, Y6 and the proposed Y3 receptors that are found in mammalian GPCR repertoires were not detected in the Fugu data-set. This sub-class gets its name from the fact that all NPY receptors bind with high affinity to the NPY and PYY peptides (with the exception of the Y4 receptors which prefer the peptide PP for binding).

\section{$\gamma$-rhodopsins (14 receptors)}

This classification contains receptors that bind to both peptides and lipid-like compounds. The $\gamma$-rhodopsins of Fugu comprise of 14 receptors (in comparison with the 42 Tetraodon nigroviridis, 59 human and 46 chicken receptors that are placed in this category of rhodopsins) and are divided in to three main branches, namelySOG (somatostatin, opioid and the neuropeptide galanin and RF-amide receptors), Melanin-concentrating hormone $(\mathrm{MCH})$ and the chemokine receptor clusters. In Fugu, 6 SOG were detected out which 3 were classified as Neuropeptide galanin \& the RF-amide binding receptor GALR and the remaining 3 as Somatostatin receptors (SSTRs 2 and 5). Opioids, which are receptors that are targeted for treating cough, pain and alcoholism, were not detected in Fugu. Two $\mathrm{MCH}$ receptors were detected in the Fugu GPCR repertoire, with representatives in both the $\mathrm{MCH} 1$ and $\mathrm{MCH} 2$ types, as in the case seen in mammals, though the latter seems to have been lost in chicken. The chemokine receptor cluster is an interesting group in this sub-class pertaining to their role in acute and chronic inflammation. Only one drug (for HIV treatment) has received regulatory approval that targets a chemokine called CCR5, which are used as co-receptors by some HIV strains during viral entry. In Fugu, 6 classic chemokines have been detected that comprise interleukin 8 receptors type I and II.

\section{$\delta$-rhodopsins (60 receptors)}

The final group of the rhodopsin sub-family is the $\delta$-rhodopsins that have four main branches of MASrelated, glycoprotein, purine and the olfactory receptors clusters. In the Fugu GPCR dataset, the olfactory receptors form the major chunk of this sub-class, including 56 out of the 60 total $\delta$-rhodopsins, in comparison to the 75, 518 and 290 such receptors found in Tetraodon nigroviridis, human and chicken, respectively. The remaining four receptors are representatives of the LHCGR ( 1 member) and the 3 members of the Relaxin-binding receptor sub-groups. The classic glycoprotein receptor hormones of LHCGR, FSHR and the TSHRs are members of the glycoprotein receptor subgroup which have been targets of recombinant peptides in different GPCR studies [29]. Out of the 56 olfactory receptors in Fugu, 50 belong to the Odorant receptors, while the human genome has 388 functional odorant receptors [30,31], 229 such representatives are found in chicken and 23 odorant candidate receptors in the Tetraodon nigroviridis GPCR repertoire. Other than the same10 odorant receptors of the Fugu $\delta$-rhodopsins, all other members were orthologous to 
the human and GPCR sub-sets. In fact, these were the only 10 receptors which did not have any human orthologs. The orphan GPCRs in Tetraodon nigroviridis could not be compared to those in Fugu as they were not grouped under any sub-families, unlike the latter. The high variability in the number of odorant genes in pisces indicates species-specific adaptation suited to bind to important receptors important to the specific species [11]. Six Fugu olfactory receptors could not be classified under any sub-category and hence, were placed under Other Olfactory Receptors.

The rapidly evolving class of olfactory GPCRs express themselves in the olfactory epithelium, with the help of which pisces, aves and mammals are known to detect the chemicals in their external environment. Olfactory receptors, on the basis of phylogenetic criteria [30,31], can broadly be categorized as those which recognize water-soluble odorants (Class I, which has been detected in both teleosts, including Fugu, and mammals, but lacking in chicken), and those that mediate airborne smells (Class II, present in chicken and mammals, but not found in Fugu). Fishes use their olfactory system to detect pheromones for discriminating between toxins, predators, prey and mates, foraging, detecting nests and staying with their own school. Since majority of fishes lead a totally aquatic life, without ever leaving the water, they have no use for the Class II olfactory receptors. An olfactory receptor may bind to a diverse set of odorants and bring about activation. This may be the reason that as compared to fishes, mammals, especially humans, have an enormous number of odorant receptors of both the Class I and Class II types to enable them to discriminate between a plethora of smells. The characterization of these receptors would be of great impact and could be capitalized upon by the fragrance industry, though not so much as drug targets as they are yet to be implicated in the occurrence of any disease.

The two pufferfishes, Fugu and Tetraodon nigroviridis, have coding regions with approximately $87 \%$ similarity and both are considered model systems for studying human GPCRs [32]. Fugu and Tetraodon nigroviridis are separated by 18 to 30 million years that might add to the differences in their gene sequences. On account of its small size, availability and easier maintenance conditions, Tetraodon nigroviridis was the species of choice over Fugu initially. But following the first draft of the Fugu genome, revealing the huge similarity observed in three-fourth of Fugu proteins with that of humans, the comparability of their gene repertoire (as well as that of other vertebrates) was established and Fugu was accepted as a model system. The differences between the two pufferfishes might be due the fact that the two fishes differ in their natural habitat and thus have different environmental conditions to adapt to. But the study of both these systems adds to the annotation of both these species and is non-redundant.

\section{Conclusions}

The phylogenetic analysis of GPCRs in the model system of Fugu helps to establish the position of fishes in the vertebrate evolution. The Fugu genome is one of the smallest vertebrate genomes that lack the repetitive sequences observed in genomes of higher organisms. It serves as a valuable reference set for studying other protein families in the human genome. We believe that a thorough understanding of the similarities and uniqueness of GPCRs among different genomes is vital before using them as drug targets. Moreover, such evolutionary studies with representatives of key vertebrate classes will help in identifying prime functional residues and motifs to elucidate the role of GPCRs in vertebrate evolution.

\section{Methods}

\section{Sequence retrieval of Fugu GPCRs}

Sequence database search was carried out on the Takifugu rubripes genome using 'G Protein Coupled Receptors in Takifugu rubripes' as the keywords. The sequence databases were re-checked with the individual receptortypes for more sequences. The sequences were extracted in the FASTA format using the Entrez search engine of National Center for Biotechnology Information (NCBI) [13], and Text Search of the Universal Protein Resource (UniProtKB) [14], which are search engines of the two non-redundant, publicly available databases and also from previously published literature [2]. The accession numbers for all the FASTA sequences can be found in the Additional File 1. The sequences retrieved were cross-checked using the NCBI Conserved Domain Database [33] for the 7TM conserved domain, which is a hallmark of GPCRs.

\section{Classification and ortholog detection}

The initial data set was classified using the IUPHARDatabase [34], PRED-GPCR database [6], BIAS-PROFS (Bioinformatics, Immunology and Algorithms make Short work of PROtein Function classification) [35], GPCRDB (Information System for G Protein-Coupled Receptors) [36] and references from previously published papers [1,3,12,16,24,28,37-46] (Additional File 1).

We detected orthologous relationships between genes of Fugu, human and chicken using systematic similarity searches at the protein level. Taking the dataset of the classified receptors, we compared it with the human and chicken genomes using NCBI Protein BLAST [47] with an extremely stringent similarity expect threshold of $1 \times 10^{-6}$ for orthology detection [48]. 


\section{Phylogenetic analysis}

The Fugu GPCRs were broadly classified into NonRhodopsins and Rhodopsins and their respective subfamilies. The sequences of all the proteins (in FASTA format) were then combined into one file for performing multiple sequence alignment employing the JTT200 protein weight matrix in the MAFFT version 6.624 [49], using E-INS-I with a gap opening penalty of 1.53 and default offset value. SEQBOOT from the PHYLIP package [version 3.68] [49] was used on the ensuing datasets (i.e. the multiple sequence alignment files) and they were bootstrapped 1000 times. Subsequently 1000 (JTT) distance matrices were obtained using PROTDIST. The neighbor-joining method was employed through the NEIGHBOR program and CONSENSE generated a consensus of 1000 neighbour trees. Two additional multiple sequence alignment files comprising of Rhodopsins and the Non-Rhodopsins were also prepared, respectively, to get separate phylogenetic trees (their corresponding numbering in the tree has been mentioned in the Additional File 2) keeping the same parameters. The sequences were grouped based on the family identity observed with the human and chicken orthologs (Additional File 3). Sequences were categorized as 'Other 7TM' if they did not match the properties of any family of the GRAFS classification system.

\section{Additional material}

Additional File 1: Table of Classification of the 316 GPCR receptors of Fugu according to the GRAFS classification system.

Additional File 2: Table enlisting all the Fugu GPCR sequences in the dataset and their corresponding names and numbering used in phylogenetic study using PHYLIP (version 3.68).

Additional File 3: Table enlisting the orthologs of Fugu GPCRs in the human, chicken and Tetraodon nigroviridis GPCR sub-sets.

\section{List of abbreviations used}

GPCRs: G protein-coupled receptors; TM: trans-membrane; MC: melanocortin; GRAFS: Glutamate, Rhodopsin, Adhesion, Frizzled/TAS2, Secretin.

\section{Acknowledgements \\ The authors acknowledge the Bioinformatics facility at the Distributed Information Sub Centre, Department of Biochemical Engineering and Biotechnology, IIT Delhi, supported by the Department of Biotechnology (DBT), Govt. of India, New Delhi. \\ This article has been published as part of BMC Bioinformatics Volume 12 Supplement 1, 2011: Selected articles from the Ninth Asia Pacific Bioinformatics Conference (APBC 2011). The full contents of the supplement are available online at http://www.biomedcentral.com/1471-2105/12? issue $=\$ 1$. \\ Authors' contributions \\ Corresponding author DS conceived the project; DS and AS designed the method and framework for the project. AS and SK performed the experiments and analyzed the data. DS, AS and SK wrote the manuscript.}

\section{Competing interests}

The authors declare that they have no competing interests.
Published: 15 February 2011

\section{References}

1. Fredriksson R, Lagerstrom MC, Lundin LG, Schioth HB: The G-proteincoupled receptors in the human genome form five main families. Phylogenetic analysis, paralogon groups, and fingerprints. Mol Pharmacol 2003, 63(6):1256-1272.

2. Fredriksson $\mathrm{R}$, Schioth HB: The repertoire of G-protein-coupled receptors in fully sequenced genomes. Mol Pharmacol 2005, 67(5):1414-1425.

3. Lagerstrom MC, Hellstrom AR, Gloriam DE, Larsson TP, Schioth HB, Fredriksson R: The $G$ protein-coupled receptor subset of the chicken genome. PLoS Comput Biol 2006, 2(6):e54.

4. Kamesh N, Aradhyam GK, Manoj N: The repertoire of G protein-coupled receptors in the sea squirt Ciona intestinalis. BMC Evol Biol 2008, 8:129.

5. Perez DM: The evolutionarily triumphant G-protein-coupled receptor. Mol Pharmacol 2003, 63(6):1202-1205.

6. Papasaikas PK, Bagos PG, Litou ZI, Promponas VJ, Hamodrakas SJ: PREDGPCR: GPCR recognition and family classification server. Nucleic Acids Res 2004, 32(Web Server issue):W380-382.

7. Gudermann T, Schoneberg T, Schultz G: Functional and structural complexity of signal transduction via G-protein-coupled receptors. Annu Rev Neurosci 1997, 20:399-427.

8. Wise A, Gearing K, Rees S: Target validation of G-protein coupled receptors. Drug Discov Today 2002, 7(4):235-246.

9. New DC, Wong JT: The evidence for G-protein-coupled receptors and heterotrimeric $\mathrm{G}$ proteins in protozoa and ancestral metazoa. Biol Signals Recept 1998, 7(2):98-108.

10. Rompler H, Staubert C, Thor D, Schulz A, Hofreiter M, Schoneberg T: G protein-coupled time travel: evolutionary aspects of GPCR research. $\mathrm{Mol}$ Interv 2007, 7(1):17-25.

11. Metpally RP, Sowdhamini R: Genome wide survey of G protein-coupled receptors in Tetraodon nigroviridis. BMC Evol Biol 2005, 5:41.

12. Schioth HB, Fredriksson R: The GRAFS classification system of G-protein coupled receptors in comparative perspective. Gen Comp Endocrinol 2005, 142(1-2):94-101.

13. Sayers EW, Barrett T, Benson DA, Bryant SH, Canese K, Chetvernin V, Church DM, DiCuccio M, Edgar R, Federhen S, et al: Database resources of the National Center for Biotechnology Information. Nucleic Acids Res 2009, 37(Database issue):D5-15.

14. The Universal Protein Resource (UniProt) 2009. Nucleic Acids Res 2009, 37(Database issue):D169-174

15. Attwood TK, Findlay JB: Fingerprinting G-protein-coupled receptors. Protein Eng 1994, 7(2):195-203.

16. Bjarnadottir TK, Fredriksson R, Schioth HB: The adhesion GPCRs: a unique family of $G$ protein-coupled receptors with important roles in both central and peripheral tissues. Cell Mol Life Sci 2007, 64(16):2104-2119.

17. McKnight AJ, Gordon S: The EGF-TM7 family: unusual structures at the leukocyte surface. J Leukoc Biol 1998, 63(3):271-280.

18. Stacey M, Lin HH, Gordon S, MCKnight AJ: LNB-TM7, a group of seventransmembrane proteins related to family-B G-protein-coupled receptors. Trends Biochem Sci 2000, 25(6):284-289.

19. Harmar AJ: Family-B G-protein-coupled receptors. Genome Biol 2001 2(12):REVIEWS3013.

20. Visser L, de Vos AF, Hamann J, Melief MJ, van Meurs M, van Lier RAW, Laman JD, Hintzen RQ: Expression of the EGF-TM7 receptor CD97 and its ligand CD55 (DAF) in multiple sclerosis. Journal of Neuroimmunology 2002, 132(1-2):156-163.

21. Hamann J, Wishaupt JO, van Lier RA, Smeets TJ, Breedveld FC, Tak PP: Expression of the activation antigen CD97 and its ligand CD55 in rheumatoid synovial tissue. Arthritis Rheum 1999, 42(4):650-658.

22. Gray JX, Haino M, Roth MJ, Maguire JE, Jensen PN, Yarme A, StetlerStevenson MA, Siebenlist U, Kelly K: CD97 is a processed, seventransmembrane, heterodimeric receptor associated with inflammation. $\mathrm{J}$ Immunol 1996, 157(12):5438-5447.

23. Nordstrom KJ, Lagerstrom MC, Waller LM, Fredriksson R, Schioth HB: The Secretin GPCRs descended from the family of Adhesion GPCRs. Mol Biol Evol 2009, 26(1):71-84.

24. Cardoso JC, Clark MS, Viera FA, Bridge PD, Gilles A, Power DM: The secretin G-protein-coupled receptor family: teleost receptors. $J \mathrm{Mol}$ Endocrinol 2005, 34(3):753-765. 
25. Lagerstrom MC, Klovins J, Fredriksson R, Fridmanis D, Haitina T, Ling MK, Berglund MM, Schioth HB: High affinity agonistic metal ion binding sites within the melanocortin 4 receptor illustrate conformational change of transmembrane region 3. J Biol Chem 2003, 278(51):51521-51526.

26. Ringholm A, Fredriksson R, Poliakova N, Yan YL, Postlethwait JH, Larhammar D, Schioth HB: One melanocortin 4 and two melanocortin 5 receptors from zebrafish show remarkable conservation in structure and pharmacology. J Neurochem 2002, 82(1):6-18.

27. Haitina T, Klovins J, Andersson J, Fredriksson R, Lagerstrom MC, Larhammar D, Larson ET, Schioth HB: Cloning, tissue distribution, pharmacology and three-dimensional modelling of melanocortin receptors 4 and 5 in rainbow trout suggest close evolutionary relationship of these subtypes. Biochem J 2004, 380(Pt 2):475-486.

28. Klovins J, Haitina T, Fridmanis D, Kilianova Z, Kapa I, Fredriksson R, GalloPayet N, Schioth HB: The melanocortin system in Fugu: determination of POMC/AGRP/MCR gene repertoire and synteny, as well as pharmacology and anatomical distribution of the MCRs. Mol Biol Evol 2004 21(3):563-579.

29. Tyndall JD, Sandilya R: GPCR agonists and antagonists in the clinic. Med Chem 2005, 1(4):405-421

30. Niimura $Y$, Nei M: Evolution of olfactory receptor genes in the human genome. Proc Natl Acad Sci U S A 2003, 100(21):12235-12240.

31. Glusman G, Bahar A, Sharon D, Pilpel Y, White J, Lancet D: The olfactory receptor gene superfamily: data mining, classification, and nomenclature. Mamm Genome 2000, 11(11):1016-1023.

32. Bolland DJ, Hewitt JE: Intron loss in the SART1 genes of Fugu rubripes and Tetraodon nigroviridis. Gene 2001, 271(1):43-49.

33. Marchler-Bauer A, Anderson JB, Derbyshire MK, DeWeese-Scott C, Gonzales NR, Gwadz M, Hao L, He S, Hurwitz DI, Jackson JD, et al: CDD: a conserved domain database for interactive domain family analysis. Nucleic Acids Res 2007, 35(Database issue):D237-240.

34. Harmar AJ, Hills RA, Rosser EM, Jones M, Buneman OP, Dunbar DR, Greenhill SD, Hale VA, Sharman JL, Bonner Tl, et al: IUPHAR-DB: the IUPHAR database of $\mathrm{G}$ protein-coupled receptors and ion channels. Nucleic Acids Res 2009, 37(Database issue):D680-685.

35. Davies MN, Secker A, Freitas AA, Mendao M, Timmis J, Flower DR: On the hierarchical classification of $\mathrm{G}$ protein-coupled receptors. Bioinformatics 2007, 23(23):3113-3118.

36. Horn F, Bettler E, Oliveira L, Campagne F, Cohen FE, Vriend G: GPCRDB information system for $G$ protein-coupled receptors. Nucleic Acids Res 2003, 31(1):294-297.

37. Naito T, Saito Y, Yamamoto J, Nozaki Y, Tomura K, Hazama M, Nakanishi S, Brenner S: Putative pheromone receptors related to the Ca2+-sensing receptor in Fugu. Proc Natl Acad Sci U S A 1998, 95(9):5178-5181.

38. Ikemoto T, Park MK: Chicken RFamide-related peptide $(\mathrm{GnIH})$ and two distinct receptor subtypes: identification, molecular characterization, and evolutionary considerations. J Reprod Dev 2005, 51(3):359-377.

39. Cardoso JC, Pinto VC, Vieira FA, Clark MS, Power DM: Evolution of secretin family GPCR members in the metazoa. BMC Evol Biol 2006, 6:108.

40. Gloriam DE, Bjarnadottir TK, Yan YL, Postlethwait JH, Schioth HB, Fredriksson R: The repertoire of trace amine G-protein-coupled receptors: large expansion in zebrafish. Mol Phylogenet Evol 2005, 35(2):470-482.

41. Ishimaru Y, Okada S, Naito H, Nagai T, Yasuoka A, Matsumoto I, Abe K: Two families of candidate taste receptors in fishes. Mech Dev 2005, 122(12):1310-1321

42. Krietsch T, Fernandes MS, Kero J, Losel R, Heyens M, Lam EW, Huhtaniemi I, Brosens JJ, Gellersen B: Human homologs of the putative $G$ proteincoupled membrane progestin receptors (mPRalpha, beta, and gamma) localize to the endoplasmic reticulum and are not activated by progesterone. Mol Endocrinol 2006, 20(12):3146-3164.

43. Fredriksson R, Hoglund PJ, Gloriam DE, Lagerstrom MC, Schioth HB: Seven evolutionarily conserved human rhodopsin $\mathrm{G}$ protein-coupled receptors lacking close relatives. FEBS Lett 2003, 554(3):381-388.

44. Tang YT, Hu T, Arterburn M, Boyle B, Bright JM, Emtage PC, Funk WD: PAQR proteins: a novel membrane receptor family defined by an ancient 7-transmembrane pass motif. J Mol Evol 2005, 61(3):372-380.

45. Oh DY, Kim K, Kwon HB, Seong JY: Cellular and molecular biology of orphan G protein-coupled receptors. Int Rev Cytol 2006, 252:163-218.

46. Kristiansen K: Molecular mechanisms of ligand binding, signaling, and regulation within the superfamily of G-protein-coupled receptors: molecular modeling and mutagenesis approaches to receptor structure and function. Pharmacol Ther 2004, 103(1):21-80.

47. Johnson M, Zaretskaya I, Raytselis Y, Merezhuk Y, McGinnis S, Madden TL: NCBI BLAST: a better web interface. Nucleic Acids Res 2008, 36(Web Server issue):W5-9.

48. Moreno-Hagelsieb G, Latimer K: Choosing BLAST options for better detection of orthologs as reciprocal best hits. Bioinformatics 2008, 24(3):319-324

49. Katoh $\mathrm{K}$, Toh $\mathrm{H}$ : Recent developments in the MAFFT multiple sequence alignment program. Brief Bioinform 2008, 9(4):286-298.

doi:10.1186/1471-2105-12-S1-S3

Cite this article as: Sarkar et al:: The G protein-coupled receptors in the pufferfish Takifugu rubripes. BMC Bioinformatics 2011 12(Suppl 1):S3.

\section{Submit your next manuscript to BioMed Central and take full advantage of:}

- Convenient online submission

- Thorough peer review

- No space constraints or color figure charges

- Immediate publication on acceptance

- Inclusion in PubMed, CAS, Scopus and Google Scholar

- Research which is freely available for redistribution 